\title{
Lack of Association Between Perlecan Gene Intron 6 BamHI Polymorphism and Risk of Mitral Valve Prolapse in Taiwan Chinese
}

\author{
Hsiang-Tai CHOU, ${ }^{1} \mathrm{MD}$, Yng-Tay CHEN, ${ }^{2} \mathrm{MS}$, Jer-Yuarn $\mathrm{Wu},{ }^{2} \mathrm{PhD}$, \\ and Fuu-Jen TSAI, ${ }^{2} \mathrm{MD}$
}

\begin{abstract}
SUMMARY
Abnormalities of proteoglycan, collagen, and elastic fibers were found in floppy mitral valves. Perlecan is one of the three major classes of heparan sulfate proteoglycans within the cardiovascular system. The role of perlecan genetic variant in mitral valve prolapse (MVP) has not been studied. We therefore performed a case-controlled study investigating the possible relation between the perlecan gene intron $6 \mathrm{BamHI}$ polymorphism and MVP among the Chinese population in Taiwan.

We studied 100 patients with MVP diagnosed by echocardiography and 100 age- and sex-matched normal control subjects. The perlecan gene intron 6 BamHI polymorphism was identified by polymerase chain reaction-based restriction analysis.

There were no significant differences in either the genotype distribution or allelic frequencies between MVP cases and controls for perlecan gene intron 6 BamHI polymorphism ( $P=0.20$ and 0.76 , respectively). Further categorization of the MVP patients into mild and severe subgroups also revealed no statistical difference from controls for perlecan gene intron 6 BamHI polymorphism.

It is concluded that perlecan gene intron 6 BamHI polymorphism is not a suitable genetic marker of MVP in Taiwan Chinese (Jpn Heart J 2004; 45: 109-118)
\end{abstract}

Key words: Perlecan gene polymorphism, Mitral valve prolapse, Taiwan

Mitral valve prolapse (MVP) appears to be one of the most common cardiac valvular disorders. It is characterized by a redundant, floppy mitral valve, sometimes complicated by prolapse and mitral regurgitation. Myxomatous degeneration of the valve leaflets is recognized as a characteristic histological change in floppy mitral valves (FMV). ${ }^{1,2)}$ FMV leaflets have a large central zone of loose myxomatous connective tissue. Histochemically, the myxomatous changes correspond to accumulations of proteoglycans. ${ }^{2)}$ This zone focally extends into the fibrosa, producing disruption of the collagen. In the myxomatous areas, the collagen

From the ${ }^{1}$ Division of Cardiology, Department of Medicine and ${ }^{2}$ Department of Pediatrics, Medical Research and Medical Genetics, China Medical College Hospital, Taichung, Taiwan.

Address for correspondence: Hsiang-Tai Chou, MD, Division of Cardiology, Department of Medicine, China Medical College Hospital, 2 Yuh Der Road, Taichung 404, Taiwan.

Received for publication May 20, 2003.

Revised and accepted July 7, 2003. 
bundles are short, fragmented, disoriented, and separated by proteoglycans. Myxomatous areas with associated collagen dissolution are present in the fibrosa and chordae tendineae of FMV. ${ }^{3)}$ The structural changes in the arrangement of both the amorphous elastin core and the microfibrils of elastic fibers associated with an increase in the number and a decrease in the size of the elastic fibers have been examined in myxomatous areas of FMV. ${ }^{4}$ These alterations in the connective tissue of FMV are involved in the pathological process. ${ }^{3,4)}$ Nevertheless, the pathogenesis of the connective tissue changes in FMV remains uncertain.

Heparan sulfate proteoglycans (HSPGs) are a family of highly charged macromolecules consisting of different core proteins with covalently linked sulfated polysaccharide chains (heparan sulfates) of varying monosaccharide sequences which serve as protein ligands mediating many biological processes. ${ }^{5}$ HSPGs are essential components of cell surfaces and extracellular matrices in the cardiovascular system. The perlecan, sydecan, and glypican core protein families constitute the major HSPGs generated within the cardiovascular system. ${ }^{6)}$ Perlecan, a multidomain heparan sulfate proteoglycan, is an intrinsic component of all basement membranes and extracellular matrices. It is suspected that genes coding for perlecan are implicated in MVP. Schwartz-Jampel syndrome is a rare autosomal recessive skeletal dysplasia associated with myotonia, and was recently ascribed to mutations of the perlecan gene. ${ }^{7)}$

The perlecan gene is located on chromosome $1 \mathrm{p} 36.1-\mathrm{p} 35$. $^{8)}$ The gene is composed of 94 exons, spanning $>120 \mathrm{kbp}$ of genomic DNA. The polymorphic intron 6 BamHI restriction site was mapped to domain I. Domain I, near the Nterminus, appears unique for the proteoglycan, since it shares no significant homology with any other proteins. Domain I contains the putative attachment sites for the heparan sulfate side chains that regulate heparan sulfate synthesis in the basement membranes and extracellular matrices. ${ }^{8,9)}$ Domain I is therefore an obvious candidate region in the search for defects associated with accumulations of proteoglycans in the myxomatous areas of FMV, and the BamHI polymorphism may be a marker of this. No other polymorphisms were reported to be identified. ${ }^{8)}$ Because there are no data currently available regarding the role of perlecan gene intron 6 BamHI polymorphism in the pathogenesis of MVP, the present study was designed to determine whether the intron 6 BamHI polymorphism (a single base substitution from thymine to guanine at the polymorphic BamHI site identified in position 97-102) of the perlecan gene is associated with the risk of MVP in the Taiwanese population. 


\section{Methods}

Study population: Patients with a mid-systolic click or a systolic murmur and various symptoms including chest pain, palpitation, anxiety, dyspnea, and insomnia who visited our cardiology clinic were examined by 2-dimensional, $\mathrm{M}$ mode, and color Doppler echocardiography. A total of 100 patients (30 men and 70 women, ranging in age from 14 to 75 , mean age, $34.1 \pm 12.7$ years) with an echocardiographically diagnosed MVP between May 2000 and August 2001 were enrolled in this study. The control group consisted of 100 age- and sexmatched healthy volunteers (38 men, 62 women, ranging in age from 16 to 76 years, mean age, $38.8 \pm 18.4$ years) with normal echocardiography verified before inclusion. All participants were of Chinese Han ethnicity and lived in central Taiwan.

The study was approved by our hospital's institutional research ethics committee and informed consent was obtained from all participants.

Echocardiography: Echocardiographic examination (Hewlett-Packard Sonos 2500, Cupertino, CA, USA) was performed according to the recommendations of the American Society of Echocardiography. ${ }^{10)}$ The diagnostic criteria of MVP included displacement of the leaflet edges, and increased thickness and redundancy of the mitral valve. ${ }^{11)}$ The degree of displacement of each leaflet in the parasternal long-axis 2-dimensional view was measured as the perpendicular from the line connecting the mid-portions of the annular hinge points to the point of greatest prolapse of each leaflet on the frame 0.1 second before mitral valve opening. Thickness of the mitral valve was measured from each leaflet of the mitral valve in diastole from the parasternal long-axis 2-dimensional view from a diastolic still frame when the leaflet was most perpendicular to the transducer. The marginal leaflet thickness was measured from the leading edge to the trailing edge at the thickest aspect of the leaflet tip. ${ }^{11)}$ The severity of mitral regurgitation was estimated in the parasternal long-axis view by color Doppler echocardiography. ${ }^{12)}$ In order to take into account the wide variability in expression of the disease, patients were classified according to the following criteria: (1) a positive diagnosis was made when patients had a redundant valve with a leaflet thickness $\geqq 4 \mathrm{~mm}$ and a total leaflet displacement $\geqq 2 \mathrm{~mm}$; (2) a case was regarded as severe when the patient had a valve thickness $>6 \mathrm{~mm}$ or a total leaflet displacement $>8$ $\mathrm{mm}$, or significant mitral regurgitation (grade $\geqq 2$ assessed according to the criteria of Miyatake, et $a l^{12)}$ ).

Genotyping of the perlecan gene intron 6 BamHI polymorphism: The genomic DNA was prepared from peripheral blood leukocytes using a genomic DNA isolation kit (Blossom, Taipei, Taiwan). Polymerase chain reactions (PCRs) were carried out to a total volume of $50 \mu \mathrm{L}$ containing genomic DNA, 2-6 pmol of each primer, $1 \mathrm{X}$ Taq polymerase buffer $(1.5 \mathrm{mM} \mathrm{MgCl} 2)$, and 0.25 units of AmpliTaq 
DNA polymerase (Perkin-Elmer, Foster City, CA, USA). The perlecan gene intron 6 BamHI polymorphism was typed by the restriction fragment length polymorphism (RFLP) method. Primers for BamHI polymorphism were (forward)

5'-CATGTCCCATGCCCCACGTGTGCT-3' and (backward)

5'-ATTGTAGCTGTGGCAGGCAAACTC-3'. The primers were designed according to the sequences of human perlecan gene. ${ }^{8)}$ The PCR amplifications were performed in a GeneAmp PCR System 2400 programmable thermal cycler (Perkin-Elmer). The cycling conditions were set as follows: one cycle at $94^{\circ} \mathrm{C}$ for 5 minutes, 35 cycles at $94^{\circ} \mathrm{C}$ for 30 seconds, $58^{\circ} \mathrm{C}$ for 30 seconds, and $72^{\circ} \mathrm{C}$ for 40 seconds, and one final cycle of extension at $72^{\circ} \mathrm{C}$ for 7 minutes. The PCR product of $250 \mathrm{bp}$ was mixed with Bam HI restriction enzyme (New England BioLabs, Beverly, MA, USA) and the reaction buffer, according to the manufacturer's instructions. Two fragments measuring 150 and $100 \mathrm{bp}$ will be present if the product is able to be digested. The reaction was then incubated at $37^{\circ} \mathrm{C}$ overnight, and then $10 \mu \mathrm{L}$ of the digested products was loaded into a $3 \%$ agarose gel with ethidium bromide staining and separated by electrophoresis. The perlecan gene intron 6 BamHI polymorphism was categorized as indivisible homozygote (TT), divisible homozygote (GG), and heterozygote (TG) (Figure).

Statistical analysis: Differences in genotype distribution between patients with MVP and control subjects were tested by a $\chi^{2}$ test with 2 degrees of freedom (df). For statistical analysis of the allelic frequency distribution in the perlecan gene

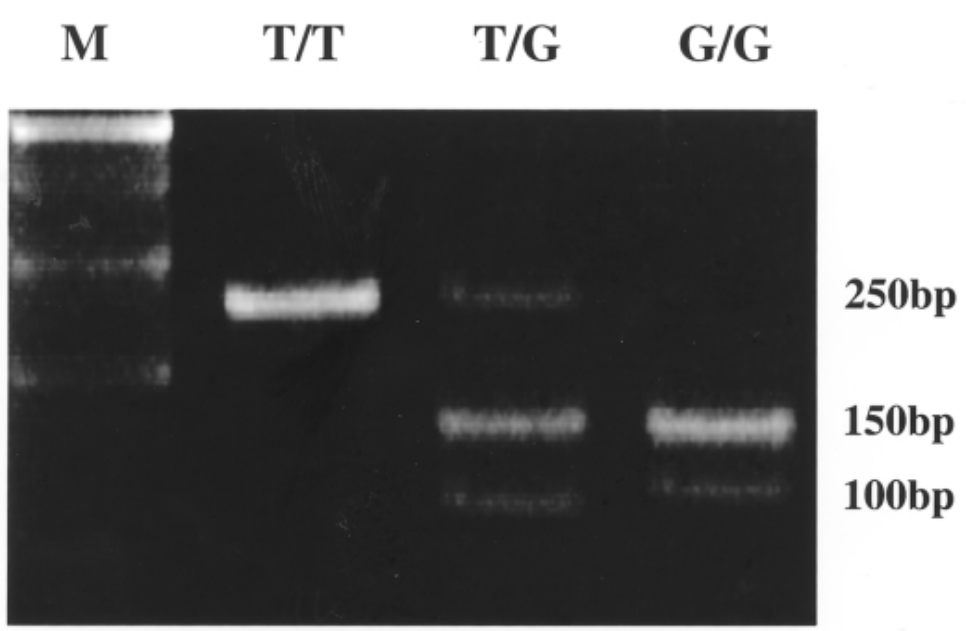

Figure. PCR-based restriction analysis of the perlecan gene intron 6 BamHI polymorphism shown on $3 \%$ agarose electrophoresis. M, 1 kb DNA size marker, TT indivisible homozygote, GG divisible homozygote, and TG heterozygote are shown. 
intron 6 BamHI polymorphism, the two groups were compared using the $\chi^{2}$ test with $1 \mathrm{df}$. Allelic frequencies were calculated from genotype frequencies in patients with MVP and control subjects. The differences among the mild, severe MVP, and control groups were estimated by a $\chi^{2}$ test with $4 \mathrm{df}$. All statistical analyses were performed with NCSS 2000 Software (Kaysville, Utah, USA). A value of $P<0.05$ was considered statistically significant.

\section{RESUlts}

Table I shows the main characteristics of the case and control groups. Blood pressure and body mass index were significantly lower in patients with MVP in comparison with control subjects. Of the 100 patients with MVP, 30 (30\%) were male and $70(70 \%)$ were female. Seventy-one $(71 \%)$ patients were 40 years old and 29 (29\%) were $>40$ years old. There were no cases of mitral chordal rupture. All patients had mitral regurgitation on color Doppler echocardiography. The mitral valvular regurgitation (MVR) was mild (grade 1+) in 72, moderate (grade $2+$ ) in 24, and moderate to severe (grade 3+) in 4. Among them, 14 males and 32 females had severe MVP. The remaining patients had mild MVP.

The distribution of perlecan genotypes and allelic frequencies among cases and controls are shown in Table II. For the perlecan gene intron 6 BamHI polymorphism, we confirmed that the genotype proportions in the control population fit the Hardy-Weinberg equilibrium estimated by the $\chi^{2}$ test. Examination of the distribution of perlecan genotypes and allelic frequencies showed no significant difference in the perlecan gene intron 6 BamHI polymorphism $\left(\chi^{2}=3.19, P=\right.$ $0.20 ; \chi^{2}=0.09, P=0.76$, respectively) between patients and controls.

Table I. Clinical Characteristics of Patients With Mitral Valve Prolapse (MVP) $(n=100)$ and Healthy Control Subjects $(n=100)$

\begin{tabular}{lcc}
\hline Parameter & MVP & Controls \\
\hline Age $(\mathrm{yrs})$ & $34.1 \pm 12.7$ & $38.8 \pm 18.4$ \\
Gender $(\mathrm{M} / \mathrm{F})$ & $30 / 70$ & $38 / 62$ \\
SBP $(\mathrm{mmHg})$ & $116.3 \pm 11.5^{*}$ & $122.6 \pm 10.8$ \\
DBP $(\mathrm{mmHg})$ & $76.2 \pm 7.8^{*}$ & $80.2 \pm 8.1$ \\
BMI $\left(\mathrm{kg} / \mathrm{m}^{2}\right)$ & $20.1 \pm 0.6^{*}$ & $20.9 \pm 1.1$ \\
\hline
\end{tabular}

Values are mean $\pm \mathrm{SD} . * P<0.01$ versus control. $\mathrm{SBP}=$ systolic blood pressure; DBP = diastolic blood pressure; $\mathrm{BMI}=$ body mass index. 
Table II. Distribution of Perlecan Intron 6 BamHI Genotypes and Their Allelic Frequencies in Patients with Mitral Valve Prolapse (MVP) $(n=100)$ and Healthy Control Subjects $(n=100)$

\begin{tabular}{|c|c|c|}
\hline - & $\begin{array}{l}\text { MVP } \\
n(\%)\end{array}$ & $\begin{array}{c}\text { Controls } \\
n(\%)\end{array}$ \\
\hline Genotype & & \\
\hline TT & $23(23)$ & $27(27)$ \\
\hline TG & $66(66)$ & $55(55)$ \\
\hline GG & $11(11)$ & $18(18)$ \\
\hline $\begin{array}{l}\text { Significance } \\
\text { Allelic frequency }\end{array}$ & \multicolumn{2}{|c|}{$\chi^{2}=3.19, P=0.20$} \\
\hline $\mathrm{T} / \mathrm{G}$ & $0.56 / 0.44$ & $0.55 / 0.45$ \\
\hline Significance & \multicolumn{2}{|c|}{$\chi^{2}=0.09, P=0.76$} \\
\hline
\end{tabular}

Genotype frequencies are indicated as absolute values (values in parentheses are percentages). Allelic frequencies are shown as fractions.

Table III. Distribution of Perlecan Intron 6 BamHI Genotypes in Patients with Mild ( $n$ $=54)$ and Severe Mitral Valve Prolapse (MVP) $(n=46)$, and Healthy Control Subjects $(n=100)$

\begin{tabular}{lccc}
\hline Genotype & $\begin{array}{c}\text { Mild MVP } \\
n(\%)\end{array}$ & $\begin{array}{c}\text { Severe MVP } \\
n(\%)\end{array}$ & $\begin{array}{c}\text { Controls } \\
n(\%)\end{array}$ \\
\hline TT & $12(22)$ & $11(24)$ & $27(27)$ \\
TG & $38(70)$ & $28(61)$ & $55(55)$ \\
GG & $4(8)$ & $7(15)$ & $18(18)$ \\
Significance & & $\chi^{2}=4.45, P=0.35$ & \\
\hline
\end{tabular}

Genotype frequencies are indicated as absolute values (values in parentheses are percentages).

As shown in Table III, there were no statistically significant differences in the distribution of perlecan gene intron 6 BamHI polymorphism $\left(\chi^{2}=4.45, P=\right.$ 0.35 ) among the mild and severe MVP subgroups and control group.

\section{Discussion}

Since Barlow's description, ${ }^{13)}$ a variety of names have been given to mitral valve prolapse, including the click-murmur syndrome, the floppy mitral valve syndrome, myxomatous mitral valve, and idiopathic mitral valve prolapse. Although most cases appear to be sporadic, echocardiographic screening of families for MVP has suggested autosomal dominant inheritance of the trait with an age and sex dependent expression. ${ }^{1415)}$ Previous linkage studies performed on a few familial MVP affected pedigrees detected by 2-dimensional echocardio- 
grams have failed to find the involvement of four collagen genes. ${ }^{16)}$ The fibrillin1gene, when mutated, causes Marfan syndrome in which MVP and annuloaortic ectasia are common. ${ }^{17)}$ Identification of the locus for autosomal dominant myxomatous MVP to chromosome 16p11.2 - p12.1 was reported. ${ }^{18)}$ In addition, Xlinked inheritance has been reported in a special form of familial MVP, called myxomatous valvular dystrophy, which has been mapped to Xq28 in a large French pedigree. ${ }^{19)}$ Low blood pressure and autonomic dysfunction may be regarded as a phenotypic feature of MVP. ${ }^{20,21)}$ The renin-angiotensin system was hypothesized to be involved in the pathogenesis of mitral valve prolapse syndrome (MVPS). ${ }^{22)}$ In recent years, an association between the angiotensin II type 1 receptor (AGTR1) gene A1166C polymorphism and MVP in a Caucasian population has been reported. ${ }^{23)}$ However, we did not find an association between AGTR1 gene A1166C polymorphism and MVP in our population. ${ }^{24}$ The difference might be caused by ethnic factors. We did observe an association between angiotensin I-converting enzyme (ACE) gene insertion/deletion (I/D) polymorphism and MVPS in our population. ${ }^{25)}$ The increased risk of MVPS associated with the I allele of the ACE was observed. We found that the patients with MVPS had a higher frequency of ACE II genotype than controls. A population-based analysis of unrelated individuals with I/D polymorphism showed an association between this polymorphism and plasma ACE levels. This association followed an additive pattern with DD and II genotypes being associated with high and low ACE levels, respectively, and ID heterozygotes being associated with an intermediate level. ${ }^{26)}$ Although the relation of I/D polymorphism and blood pressure was controversial, several studies found a significant association between I/D polymorphism and blood pressure. This finding might explain why our MVPS patients had low blood pressure. A germline mutation of the thyroid-stimulating hormone receptor (TSHR) gene was reported to be associated with thyrotoxicosis and MVPS in a Chinese family. ${ }^{27)}$ They postulated that TSHR activation might increase the clinical expression of MVP in genetically predisposed individuals. However, we did not find an association between the polymorphisms of codon 727 and 52 of the TSHR gene and MVPS in our population. ${ }^{28)}$ It is well recognized today that the FMV is the central issue in the FMV-MVP-MVR story. Histological and ultrastructural analyses of FMV show nonspecific alterations of collagen and elastin and accumulation of proteoglycans (often called myxomatous infiltration). We also observed an association between COL3A1 collagen gene exon 31 polymorphism and risk of MVP in our population. ${ }^{29)}$ The cohorts of MVP patients included in the studies of AGTR1 A1166C polymorphism, ACE I/ D polymorphism, TSHR codon 727 and 52 polymorphisms, and COL3A1 collagen gene exon 31 polymorphism were the same as those included in the present 
study. The more than one association means the MVP is a complex or multifactorial gene-associated disease.

In the FMV, myxomatous changes were observed mainly in the spongiosa and extended diffusely into other layers. The cellular components of the mitral valve leaflets, that is, fibroblasts, myofibroblasts, and poorly differentiated mesenchymal cells, were observed mainly in the spongiosa. ${ }^{4)}$ Perlecan is an intrinsic component of all basement membranes and extracellular matrices, and also appears on cell surfaces. Perlecan is secreted by multiple cell types including vascular endothelial cells, smooth muscle cells and fibroblasts, and is implicated in cell growth and differentiation, through interactions with growth factors, cell surface receptors, collagens, laminin, and other components within basement membrane and extracellular matrices. ${ }^{5-7)}$ In European insulin-dependent diabetes mellitus patients an intron 6 BamHI polymorphism at the putative heparan sulfate attachment site is reported to be associated with reduced risk of albuminuria, ${ }^{8}$ ) itself a risk factor for vascular disease in diabetic patients. Altered expression of perlecan has also been identified in proliferating vascular smooth muscle cells and has an association with the severity of atherosclerotic lesions. ${ }^{30)}$ In Australian Caucasians undergoing coronary angiography the perlecan BamHI polymorphism was reported to be associated with lower apo B levels but unrelated to the presence or absence of significant coronary artery disease in this population. ${ }^{31}$ ) The perlecan abnormality was thought to be one of the possible changes that initiated the pathological sequence in MVP. Arikawa-Hirasawa, et al. reported that they identified five different mutations that resulted in various forms of perlecan in three unrelated patients with Schwartz-Jampel syndrome (SJS). ${ }^{7)}$ The SJS mutations resulted in different forms of perlecan in reduced levels that are secreted to the extracellular matrix and are likely partially functional. This is a report regarding the relation between the perlecan genetic variants and its structure and function. Therefore, the role of perlecan genetic variants was hypothesized to be involved in the pathogenesis of MVP. The present study used a method of PCR-based restriction analysis to approach the single nucleotide polymorphism. In this case-controlled study, we did not find an association between perlecan gene intron 6 BamHI polymorphism and risk of MVP.

Since the perlecan gene polymorphism was hypothesized to be associated with the severity of MVP, we studied the distribution of the perlecan gene intron 6 BamHI polymorphism in the mild and severe MVP subgroups. Our results show no evidence of an association of the perlecan gene intron 6 BamHI polymorphism with the severity of MVP. Other factors should be considered to be involved in the progression of MVP. Reactive fibrosis is known to occur in FMV, particularly near their surfaces, presumably as a consequence of mechanical trauma related to the excessive mobility of the leaflets. ${ }^{32)}$ Transforming growth 
factor- $\beta 1$ (TGF- $\beta 1$ ) was proposed to be involved in the fibrotic process. ${ }^{33)} \mathrm{How}-$ ever, we did not find an association between TGF- $\beta 1$ gene polymorphisms and MVP in our population. ${ }^{34)}$

In conclusion, this study shows that the intron 6 BamHI polymorphism of the perlecan gene is not a suitable genetic marker of MVP among the Chinese population in Taiwan. Further studies are needed to clarify the pathogenesis of MVP.

\section{REFERENCES}

1. Frable WJ. Mucinous degeneration of the cardiac valves: the "floppy valve" syndrome. J Thorac Cardiovasc Surg 1969; 58: 62-70.

2. Ferrans VJ, Butany JW. Ultrastructural pathology of the heart. In: Trump BF, Jones RT, editors Diagnostic Electron Microscopy. Vol. 4. New York: John Wiley, 1983: 421-35.

3. Baker PB, Boudoulas H, Wooley CF. The floppy mitral valve/mitral valve prolapse/mitral valvular regurgitation: structural and physical characteristics. In: Boudoulas H, Wooley CF, editors. Mitral Valve: Floppy Mitral Valve, Mitral Valve Prolapse, Mitral Valvular Regurgitation. 2nd ed. Armonk, New York: Futura, 2000: 11542.

4. Tamura K, Fukuda Y, Ishizaki M, Masuda Y, Yamanaka N, Ferrans VJ. Abnormalities in elastic fibers and other connective tissue components of floppy mitral valve. Am Heart J 1995; 129: 1149-58.

5. Williams KJ, Fuki IV. Cell-surface heparan sulfate proteoglycans: dynamic molecules mediating ligand catabolism. Curr Opin Lipidol 1997; 8: 253-62.

6. Rosenberg RD, Shworak NM, Liu J, Schwartz JJ, Zhang LJ. Heparan sulfate proteoglycans of the cardiovascular system: specific structures emerge but how is synthesis regulated? J Clin Invest 1997; 99: 2062-70.

7. Arikawa-Hirasawa E, Le AH, Nishino I, et al. Structural and functional mutations of the perlecan gene cause Schwartz-Jampel syndrome, with myotonic myopathy and chondrodysplasia. Am J Hum Genet 2002; 70: 1368-75.

8. Hansen PM, Chowdhury T, Deckert T, Hellgren A, Bain SC, Pociot F. Genetic variation of the heparan sulfate proteoglycan gene (perlecan gene). Diabetes 1997; 46: 1658-9.

9. Dolan M, Horchar T, Rigatti B, Hassell JR. Identification of sites in domain I of perlecan that regulate heparin sulfate synthesis. J Biol Chem 1997: 272; 4316-22.

10. Henry WL, DeMaria A, Gramiak R. Report of the American Society of Echocardiography committee on nomenclature and standards in 2D echocardiography. Circulation 1980; 62: 212-20.

11. Malkowski MJ, Boudoulas H, Wooley CF, Guo R, Pearson AC. The spectrum of structural abnormalities in the floppy mitral valve echocardiographic evaluation. Am Heart J 1996; 132: 145-51.

12. Miyatake K, Izumi S, Okamoto M, et al. Semiquantitative grading of severity of mitral regurgitation by a realtime two-dimensional Doppler flow imaging technique. J Am Coll Cardiol 1986; 7: 82-8.

13. Barlow JB, Pocock WA, Marchand P, Denny M. The significance of late systolic murmur. Am Heart J 1963; 66: 443-52.

14. Weiss AN, Mimbs JW, Ludbrook PA, Sobel BE. Echocardiographic detection of mitral valve prolapse, exclusion of false positive diagnosis and determination of inheritance. Circulation 1975; 52: 1091-6.

15. Devereux RB, Brown WT, Kramer-Fox R, Sachs I. Inheritance of mitral valve prolapse: effect of age and sex on gene expression. Ann Intern Med 1982; 97: 826-32.

16. Henney AM, Tsipouras P, Schwartz RC, Child AH, Devereux RB, Leech GJ. Genetic evidence that mutations in the COL1A1, COL1A2, COL3A1, or COL5A2 collagen genes are not responsible for mitral valve prolapse. Br Heart J 1989; 61: 292-9.

17. Milewicz DM. Molecular genetics of Marfan syndrome and Ehlers-Danlos type IV. Curr Opin Cardiol 1998; 13: 198-204. 
18. Disse S, Abergel E, Berrebi A, et al. Mapping of a first locus for autosomal dominant myxomatous mitral valve prolapse to chromosome 16p11.2-p12.1. Am J Hum Genet 1999; 65: 1242-51.

19. Kyndt F, Schott JJ, Trochu JN, et al. Mapping of X-linked myxomatous valvular dystrophy to chromosome Xq28. Am J Hum Genet 1998; 62: 627-32.

20. Devereux RB, Brown WT, Lutas EM, Kramer-Fox R, Laragh JH. Association of mitral valve prolapse with low body weight and low blood pressure. Lancet 1982; 2: 792-5.

21. Boudoulas H. Mitral valve prolapse: etiology, clinical presentation and neuroendocrine function. J Heart Valve Dis 1992; 1: 175-88.

22. Zdrojewski TR, Wyrzykowski B, Krupa-Wojciechowska B. Renin-aldosterone regulation during upright posture in young men with mitral valve prolapse syndrome. J Heart Valve Dis 1995; 4: $236-41$.

23. Szombathy T, Janoskuti L, Szalai C, et al. Angiotensin II type 1 receptor gene polymorphism and mitral valve prolapse syndrome. Am Heart J 2000; 139: 101-5.

24. Chou HT, Shi YR, Wu JY, Tsai FJ. Angiotensin II type 1 receptor gene Adenine/Cytosine1166 polymorphism is not associated with mitral valve prolapse syndrome in Taiwan Chinese. Circ J 2002; 66: 163-6.

25. Chou HT, Chen YT, Shi YR, Tsai FJ. Association between angiotensin I-converting enzyme gene insertion/ deletion polymorphism and mitral valve prolapse syndrome. Am Heart J 2003; 145: 169-73.

26. Rigat B, Hubert C, Alhenc-Gelas F, Cambien F, Corvol P, Soubrier F. An insertion/deletion polymorphism in the angiotensin I-converting enzyme gene accounting for half the variance of serum enzyme levels. J Clin Invest 1990; 86: 1343-6.

27. Khoo DHC, Parma J, Rajasoorya C, Ho SC, Vassart G. A germline mutation of the thyrotropin receptor gene associated with thyrotoxicosis and mitral valve prolapse in a Chinese family. J Clin Endocrinol Metab 1999; 84: 1459-62.

28. Chou HT, Shi YR, Chang CT, Tsai FJ. The polymorphisms of codon 727 and 52 of thyroid-stimulating hormone receptor gene are not associated with mitral valve prolapse syndrome in Taiwan Chinese. Jpn Heart J 2002; 43: 655-66.

29. Chou HT, Chen YT, Wu JY, Tsai FJ. Association between COL3A1 collagen gene exon 31 polymorphism and mitral valve prolapse. Int J Cardiol 2004. (in press)

30. Radhakrishnamurthy B, Tracy RE, Dalferes ER Jr., Berenson GS. Proteoglycans in human coronary arteriosclerotic lesions. Exp Mol Pathol 1998; 65: 1-8.

31. Cai H, Wang XL, Wilcken DEL. Genetic polymorphism of heparan sulfate proteoglycan (perlecan, HSPG2), lipid profiles and coronary artery disease in the Australian population. Atherosclerosis 2000; 148: 125-9.

32. Guthrie RB, Edwards JE. Pathology of the myxomatous mitral valve: nature, secondary changes and complications. Minn Med 1976; 59: 637-47.

33. Ignotz R, Massague J. Transforming growth factor- $\beta$ stimulates the expression of fibronectin and collagen and their incorporation into the extracellular matrix. J Biol Chem 1986; 261: 4337-45.

34. Chou HT, Shi YR, Hsu Y, Tsai FJ. Lack of association between transforming growth factor- $\beta 1$ gene polymorphism and mitral valve prolapse in Taiwan Chinese. J Heart Valve Dis 2002; 11: 478-84. 